\title{
OPTIMIZED MULTI LAYER PERCEPTRON ARTIFICIAL NEURAL NETWORK BASED FAULT DIAGNOSIS OF INDUCTION MOTOR USING VIBRATION SIGNALS
}

\author{
Tarek KHOUALDIA ${ }^{1}$, Abdelaziz LAKEHAL ${ }^{1}$, Zoubir CHELLI ${ }^{2}$, Kais KHOUALDIA ${ }^{1}$, \\ Karim NESSAIB ${ }^{1}$ \\ ${ }^{1}$ Department of Mechanical Engineering, Mohamed Chérif Messaadia University, P.O. Box 1553, Souk-Ahras, \\ 41000, Algeria t.khoualdia@univ-soukahras.dz, lakehal21@yahoo.fr, a.lakehal@univ-soukahras.dz, \\ k.khoualdia@univ-soukahras.dz, nessaibkarim@gmail.com \\ ${ }^{2}$ Department of Electrical Engineering, Mohamed Cherif Messaadia University, P.O. Box 1553, Souk-Ahras, \\ 41000, Algeria. E-mail: zoubir.chelli@univ-soukahras.dz
}

\begin{abstract}
Installations and the detection of their faults has become a major challenge. In order to develop a reliable approach for monitoring and diagnosis faults of these components, a test rig was mounted. In this article, a Multi Layer Perceptron (MLP) Artificial Neural Network (ANN) has been structured and optimized for online monitoring of induction motors. The input layer of our ANN used eight indicators calculated from the collected time signals and which represent the different states of the motor (Healthy, broken rotor bars, bearing fault and Misalignment) and the output layer used a codified matrix. However, based on L27 Taguchi design, the architecture for the hidden layers of our network is chosen, with the use of the LevenbergMarquardt learning algorithm. Garson's algorithm and connection weight approach showed that there's a great sensitivity of the crest factor, the kurtosis and the variance on the effectiveness of our diagnostic system. Consequently, the obtained results are capable of detecting faults in the induction motor under different operating conditions.
\end{abstract}

Keywords: induction motor, vibration analysis, monitoring and diagnosis, optimized artificial neural network, sensitivity analysis.

\section{INTRODUCTION}

Induction motors represent the majority of the drive means in industrial installations. Despite their greater robustness and reliability, it's very necessary to monitor their state of health and identify their faults at an early stage to optimize their availability and avoid accidental and penalizing breakdowns. Consequently, induction motor health-condition-monitoring system is very crucial for maintenance engineers and the development of reliable instrumentation and robust diagnostic techniques are very useful for the success of a predictive maintenance plan for several industries.

Among all the stages of monitoring induction motors, diagnosis is the most difficult stage. Model-based diagnosis and database-based diagnosis are the most used [1]. In the case of model-based methods the difficulty lies in the precision since an accurate numerical model is generally difficult to derive from complex electromechanical systems, in particular when the machine is operating in an uncertain noisy environment as is the case with the majority of industrial electric motors [2]. Data-driven algorithm requires a lot of historical data especially faulted one - and often they are not available by the measurement in the industry. But, in the case of the database models combined with Artificial Intelligence (AI) techniques used in the remainder of this study, when the training and testing data are available this method become simpler and more precise. Also, database models combined with AI methods gives a high rate of success and precision. It does not require any assumptions and complex mathematical models [3]. These methods are based on the recognition of fault signatures, obtained by measurement on test rigs.

The techniques used for the induction motors monitoring are electromagnetic torque analysis, acoustic signals measurements, vibration monitoring and electrical signature analysis [4-7]. In the last decades the fault diagnosis of induction motor has moved from these traditional techniques to AI techniques [8]. Artificial intelligence techniques can help to accelerate the decisionmaking process with reduced human intervention. Inference-based intelligent methods include various techniques which can be used independently or combined to improve their efficiency. Some of these techniques use expert systems [9], fuzzy logic [10], artificial neural networks (ANNs) [11], Bayesian inference [12], genetic algorithms (GA) [13], and SVM [14], etc. Other combined tools use Fuzzy Logic ANN [15], Recurrent Neural Networks and Dynamic Bayesian networks [16], and Neuro-Genetic Algorithm [17].

The literature shows that ANNs are very efficient in induction motor fault diagnosis. Also, it's very rich in works that discuss the use of ANN in fault diagnosis of 
induction motor. The problem here is to find the optimum ANN structure for a fast and accurate classification process. Unal et al. [18] used GA to optimizing ANN architecture. The optimized ANN is used to classify the features extracted from fault diagnosis of rolling bearings. Vilas and Sanjay [19] developed Multi Layer Perceptron (MLP) and self-organizing map neural network models. In this work simple statistical parameters are used as input feature space and Principal Component Analysis is used for reduction of input dimensionality. Yuan et al. [20] diagnosed faults in induction motor based on Radial basis function (RBF) combined Neural Network. The proposed RBF neural network hidden layers are optimized by the immune genetic algorithm. The Authors successfully performed fault diagnosis of induction motor and results of immune genetic optimized RBF neural network are significantly better than the direct result of RBF neural network in the ability of reproduction and generalization.

In vibration analysis technique, each fault in the induction motor causes a change in its vibratory behavior. By using signal processing techniques it's possible to determine this change in the behavior. Time domain analysis, frequency domain analysis, and time frequency domain analysis are the three domains used in vibration monitoring. In the objective to improve and make the induction motor fault diagnosis more reliable, statistical features extracting from time domain signal analysis of the induction motor must be integrated into the ANN. The principal features which can extract are: RMS value, kurtosis, standard deviation, higher statistical moments, etc [21]. In this paper, to step-by-step development of a reliable approach for monitoring and diagnosis faults of induction motor, the authors behind this study decided to set up an instrumented test rigs. Four machine states will be studied including healthy state and three faulty states. In other word, the variation in the raw time domain vibration signals are too small to be detected, therefore the comparison of raw time domain signals of faulty and healthy induction machine is not effective to decide on behavior change. To achieve the objectives of the study, a Multi Layer Perceptron (MLP) ANN will be structured and optimized by L27 Taguchi design for online monitoring of induction motors. The design of experiments (DOE) classical method considers only the mean values of the characteristics to be optimized. It is sometimes supplemented by an analysis of the variance of various tested factors. On the other hand, Taguchi experimental design is a multi-objective optimization method, which jointly deals with the mean and the variability of characteristics values, in our case characteristics are the constituents of our ANN hidden layer. In order to have an AI system usable on line, the DOE based on the L27 Taguchi design, were chosen to determine the best structure of the ANN at the level of the hidden layers, and the best combination of activation functions. However, based on their sensitivity to induction motors faults, the vibration indicators calculated from the signals measured in time domain were selected.

The remaining of this paper is organized as follows: Section 2 is dedicated to describe a brief introduction to vibration analysis. In Section 3, the experimental part and the vibration signals systems acquisition are presented. Section 4 presents the optimization of the developed ANN. Section 5 is devoted to the sensitivity analysis. Finally, conclusions are presented at Section 6.

\section{VIBRATION BASED MONITORING OF INDUCTION MOTORS}

Vibration of electrical machines such as induction motors can be caused by mechanical problems, including bearing fault, imbalance, misalignment and mechanical loosening and by electrical faults which the main is broken rotor bar fault. Vibration based monitoring is the most reliable technique in condition based maintenance techniques. Vibration analysis allows the diagnosis of the most mechanical and electrical faults. The literature shows that vibration and current signals analysis are the most preferred techniques for the induction motor diagnosis.

In this work the vibration analysis of three main faults which affect the induction motors are studied, the misalignment of the rotor, the broken rotor bar and the bearing fault. The misalignment of the rotor is characterized by a vibration at the frequency of rotation, the presence of the second harmonic of the network frequency modulated by the frequency of passage of poles as well as the presence of the second harmonic of the sliding frequency. The zoom analysis, envelope analysis and cepstrum are recommended for the detection of this type of rotors fault [22]. In the case of broken rotor bar faults, the vibration is characterized by the modulation of the frequency of bars passage by the second harmonic of the network frequency. The zoom or envelope analyses are recommended for broken bars [23]. However, the different faults produced of the bearing can be classified according to the damaged elements as: outer raceway fault, inner raceway fault, ball fault, and combination of bearing components fault. Each part of the bearing has an own frequency that depends of its geometry and dimensions. The fault frequency of the bearing operating at a given rotor speed is the product of multipliers with the speed of rotating shaft [24].

\section{EXPERIMENTAL STUDY}

In this work, in order to perform four cases of signal acquisition in Table 1, four induction motors used at our test rig with which the experiments were carried out.

However, a healthy motor is mounted on a test rig to collect signals without faults. For the case of the forth state in the Table, the broken rotor bar motor consists of a motor fitted with broken rotor bars as seen in the Fig. 1(a). Enough material has been removed to expose three rotor bars. In order to create the misalignment case, two jack bolts which rest directly on the outer ring of the motor bearings, as shown in Fig. 1(b), when they have been removed or are backed away from the bearing, the rotor is in the aligned state, and when they are tightened against the bearings, a misalignment is then created. The case of bearing faults, intentionally faulted bearings mounted at 
the motor, one bearing with an inner race fault and one bearing with an outer race fault, shown in Fig. 1(c).

Table I: Different cases of signal acquisition

\begin{tabular}{|l|l|l|}
\hline Cases & Induction motor state & Faults location \\
\hline 1 & Healthy & - \\
\hline 2 & Misalignment & Misalignment of the rotor \\
\hline 3 & With bearing fault & Combined bearing fault \\
\hline 4 & $\begin{array}{l}\text { With broken rotor } \\
\text { bars }\end{array}$ & $\begin{array}{l}\text { Three intentionally } \\
\text { broken bars }\end{array}$ \\
\hline
\end{tabular}

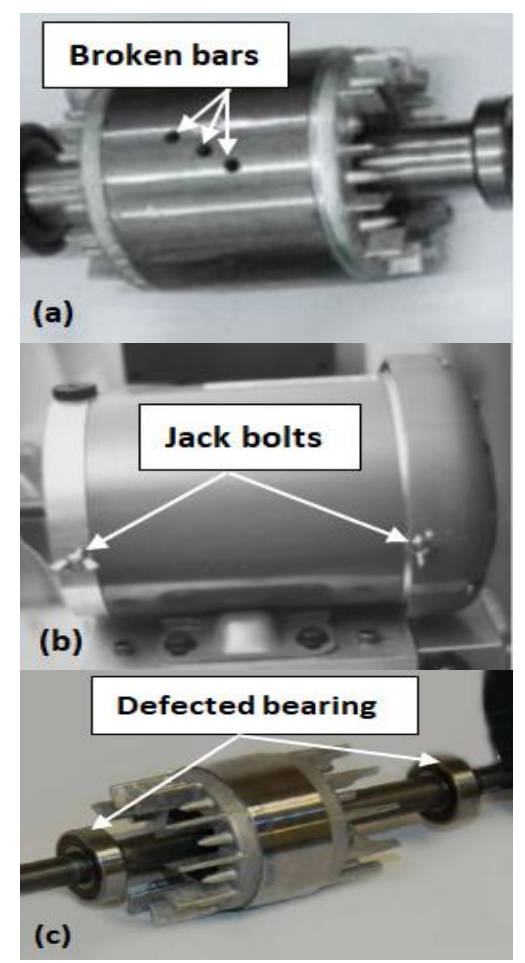

Fig. 1. Different faults of the induction motor

\subsection{Vibration signals acquisition}

Experiments were carried out on a test rig designed for the creation of several types of mechanical faults; the faults of the induction motors were maintained for the realization of several tests of the healthy motor, with broken rotor bars, with bearing faults and with rotor misalignment. Four speeds, low, high and two intermediate speeds were selected for the vibration measurements of induction motors. A triaxial piezoelectric sensor (ICP 3 Axes), with a sensitivity of $100 \mathrm{mV} / \mathrm{g}$ and a frequency range of 0,5 à $5 \mathrm{kHz}$, was used for the measurement.

However, the measurements in Fig. 2(a) show the signals of the healthy motor, with the different speeds $(600$ rpm, $900 \mathrm{rpm}, 1200 \mathrm{rpm}$ and $1500 \mathrm{rpm}$ ). Note that the
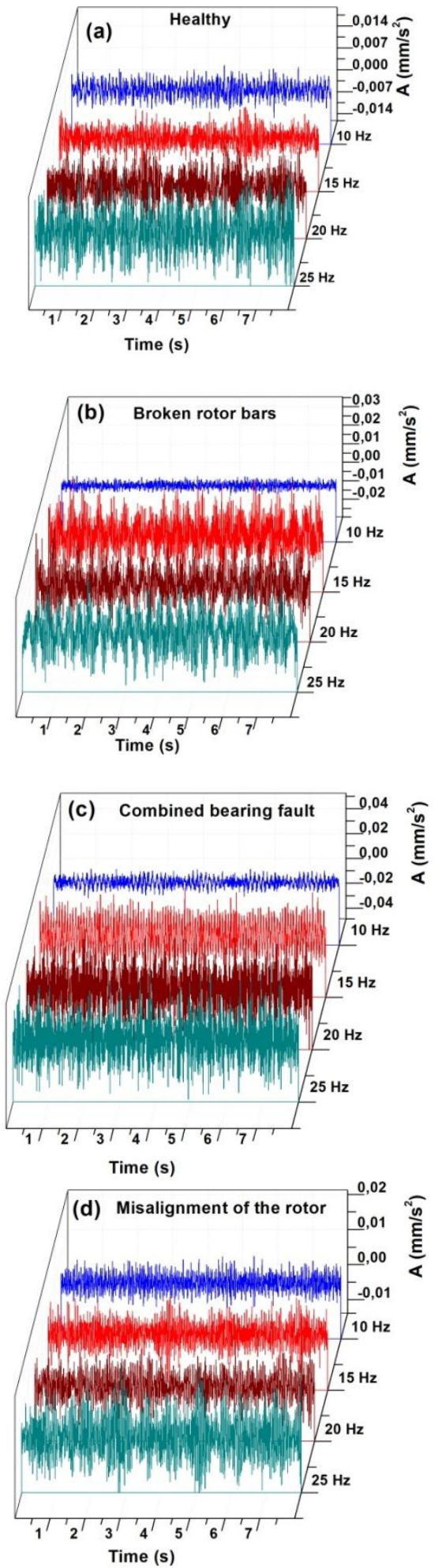

Fig. 2. Acquired signals for different speeds and states

signal amplitudes are small but increase with increasing speed. With a time of acquisition of eight seconds, measurements taken on the healthy motor, Fig. 2(a), show that signals are random with low amplitudes. The amplitudes of these signals increase with varying rotor speed and their random nature is keeping. For the states of motors with faults, we notice that the signals become pulsed. Fig. 2(b) shows the signals of the motor with three 
broken bars, the amplitude of the acceleration increases to $0.03919 \mathrm{~mm} / \mathrm{s}^{2}$ at the rotational speed of $1500 \mathrm{rpm}$. However, for the case of the motor with defective bearing shown in Fig. 2(c), the pulses of these signals are caused by repetitive impacts of the rolling elements on the chipping of the outer ring and the inner ring. For the fourth case, the rotor misalignment is represented by the pulse signals of Fig. 2(d). The maximum acceleration of the signals has the value of $0.0104 \mathrm{~mm} / \mathrm{s}^{2}$ at the rotor speed of $600 \mathrm{rpm}$ and the value of $0.02387 \mathrm{~mm} / \mathrm{s}^{2}$ at the rotor speed of $1500 \mathrm{rpm}$.

\subsection{Time domain features}

Time domain signal features are effective to reflect the different operating states of the induction motor. In order to establish the matrix of the input layer of the ANN, Eight vibration indicators, presented in Table 2, are calculated from time domain signal $[25,26]$.

Based on measured signals according to the design of control factors with Taguchi L27 $\left(3^{5}\right)$ established later, the eight indicators were calculated.

\section{ANN OPTIMIZATION}

\subsection{Empirical optimization of the ANN}

The empirical optimization method makes it possible to determine the structure of the best ANN, this method has been adopted by several researchers among them Wang et al. [27].

At the input of the ANN, there are eight indicators represented by eight neurons, and at the output there are thirty-two neurons which represent the different states of the motor. The number of neurons at the input and output layer is invariable, only the hidden layer is varied. In order to choose the optimal architecture of our ANN, we use a single hidden layer, and then we varied the number of neurons in this layer. After several learning of each ANN structure, the model (8-8-32) gave us the best results, which are the lowest MSE with the value of 0.001187 and the highest values of correlations coefficient, Learning (RL), test (RT), validation (RV) and global (Ra), as shown in the Fig. 3.
The second criterion to choose, is the activation functions (logsig, tansig and purelin), for a single hidden layer, and eight neurons in this layer, we have combined these main activation functions at the input layer, the hidden layer and output layer. However, according to the learning results of our ANN, the most powerful combination is (tansig, tansig and purelin) with the highest percentage values of the correlation coefficients (learning, global, testing and validation).

Another criterion varied is the number of hidden layers. The results showed that with a single hidden layer of eight neurons and the activation functions (tansig, tansig, and purelin), the ANN gave the best correlation coefficients and a very low MSE. According to the empirical method, with the configuration of an error back propagation network and the activation functions tansig, tansig and purelin which are respectively at the input layer, the hidden layer and the output layer, the most efficient architecture is (8-8-32). We used Levenberg-Marquardt as a learning algorithm because it converges quickly to targets compared to other algorithms [28].

However, results shown on the regression curves in the Fig. 4 are given by the learning of the ANN (8-8-32) with the selected activation functions and the Levenberg Marquardt algorithm.

\subsection{Optimization with DOE method}

In order to optimise the architecture of the ANN, a method based on the design of experiment (DOE) is chosen.

\subsubsection{Orthogonal array of Taguchi}

A Taguchi design provides a strong approach to identifying the optimum factors in hidden layer of our architecture of the ANN [29].

However, as for the previous network, for training of the neural network, $70 \%$ of the samples are used, and from the same samples, $15 \%$ are used for test and $15 \%$ for the validation.

Table II: Features from the time domain signal

\begin{tabular}{ccc}
\hline Feature & Equation & Definition \\
\hline Maximum value & $\max \left\{\left|x_{i}\right|\right\}$ & Max value of the signal \\
\hline RMS value & $\left(\frac{1}{N} \sum_{i=1}^{N} \mathrm{x}_{i}^{2}\right)^{\frac{1}{2}}$ & Root mean square of the signal \\
\hline $\begin{array}{c}\text { Mean square } \\
\text { value }\end{array}$ & $\mathrm{MSV}=\frac{1}{N} \sum_{i=1}^{N} x_{i}^{2}$ & Mean square of the signal \\
\hline Variance & $\frac{1}{N-1} \sum_{i=1}^{N}\left(\mathrm{x}_{\mathrm{i}}-\mathrm{MSV}\right)^{2}$ & Variance of the signal \\
\hline Kurtosis factor & $\left(N \sum_{i-1}^{N}\left(x_{i}-\bar{x}\right)^{4}\right) /\left(\sum_{i=1}^{N}\left(x_{i}-\bar{x}\right)^{2}\right)$ & Fourth normalized moment of the signal \\
\hline Crest factor & $\max \left|x_{i}\right| / R M S$ & Ratio of maximum amplitude to RMS \\
\hline Clearance factor & $\left(\max \left|x_{i}\right|\right) /\left(\frac{1}{N} \sum_{i=1}^{N}\left|x_{i}\right|^{\frac{1}{2}}\right)^{2}$ & Ratio of maximum amplitude to the mean \\
\hline Peak to peak & $\max x_{i}-\min x_{i}$ & value \\
\hline
\end{tabular}




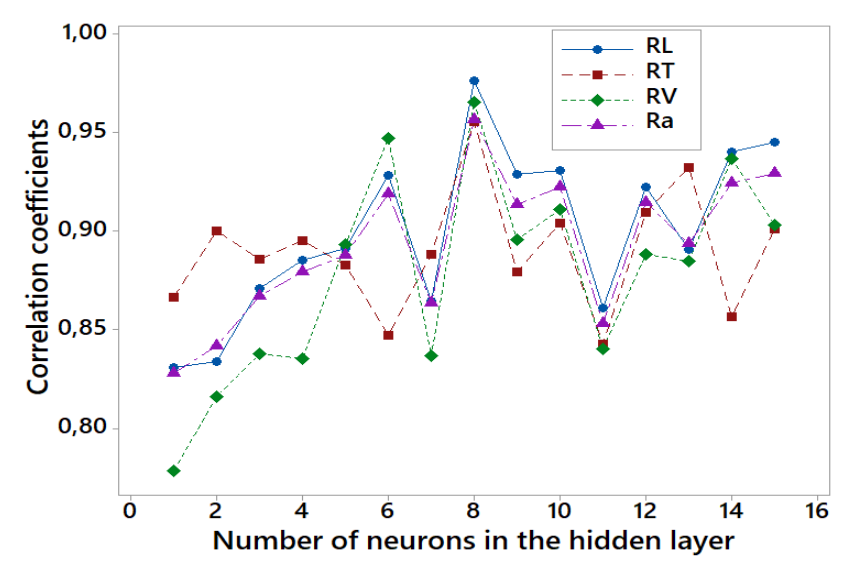

Fig. 3. Acquired signals for different speeds and states
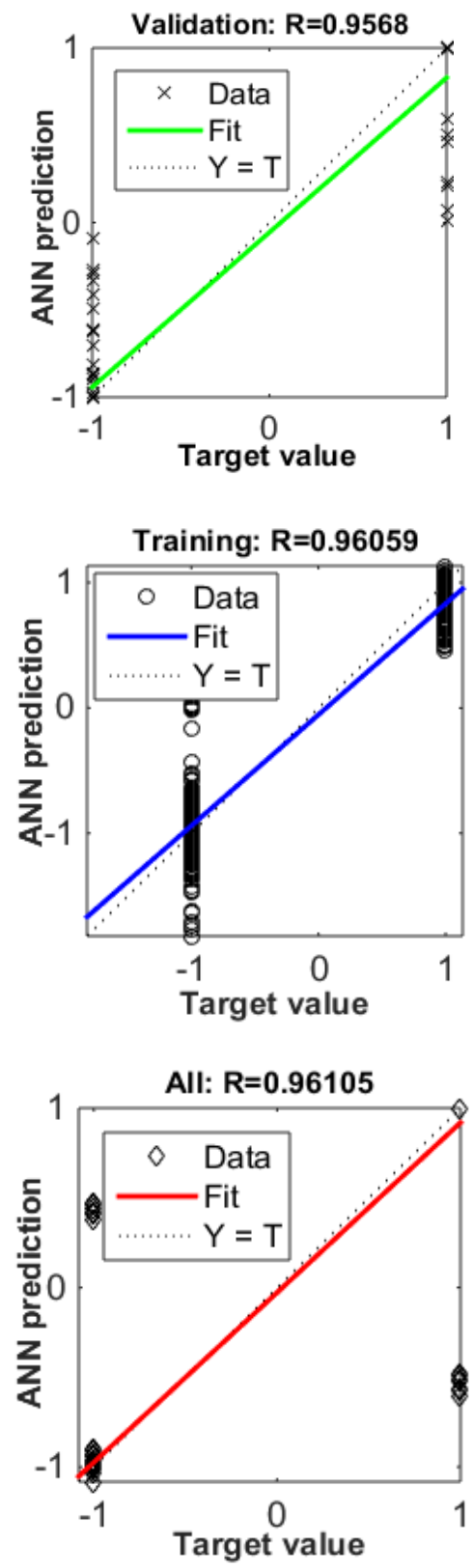

Fig. 4. Correlation coefficients of the ANN optimised with empirical method
In order to calculate the deviation between the experimental values and the desired values, the Taguchi method uses a function called a loss function converted to a signal to noise ratio $(\mathrm{S} / \mathrm{N})$ [30]. Taguchi quality characteristic is such as a smaller is the better, the higher is the better or the nominal is the best [31], the cases with respective equation are presented as following:

Higher is the better calculating as follows:

$$
\frac{S}{N} \text { ratio }=-10 \log \left(\frac{1}{n} \sum_{i=1}^{n} \frac{1}{y_{i j}^{2}}\right)
$$

Where $\mathrm{y}_{\mathrm{ij}}=\mathrm{ith}$ replicate of $\mathrm{jth}$ response, $\mathrm{n}=$ number of repetitions $=1,2, \ldots, n ; j=1,2, \ldots, k$. Eq. (1) is used to where maximization of the quality characteristic of interest is desired.

Smaller is the better:

$$
\frac{S}{N} \text { ratio }=-10 \log \left(\frac{1}{n} \sum_{i=1}^{n} y_{i j}^{2}\right)
$$

Eq. (2) is applied where minimization of the quality characteristic is desired.

Nominal is the best:

$$
\frac{S}{N} \text { ratio }=10 \log \left(\frac{\bar{y}_{j}^{2}}{s_{y}^{2}}-\frac{1}{n}\right) \approx 10 \cdot \log \left(\frac{\bar{y}_{j}^{2}}{s_{y}^{2}}\right) \text { (3) }
$$

Where, $\bar{y}=\frac{y_{1}+y_{2}+y_{3} \ldots+y_{n}}{n}$ and $s_{y}^{2}=\frac{\sum\left(y_{i}-\bar{y}\right)^{2}}{n-1}$.

The nominal is the best type where minimization of the mean squared error around a specific objective value [32].

Number of hidden layers (A), number of neurons in each hidden layer(B), activation functionsat the input layer (C), activation functions at the hidden layer (D) and activation functions at the output layer (E) were chosen as

\begin{tabular}{|c|c|c|c|c|c|}
\hline \multirow[t]{3}{*}{ Levels } & A & $\mathrm{B}$ & $\mathrm{C}$ & $\mathrm{D}$ & $\mathrm{E}$ \\
\hline & \multirow[b]{2}{*}{ 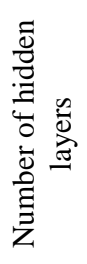 } & \multirow[b]{2}{*}{ 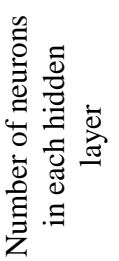 } & \multicolumn{3}{|c|}{ Activation functions } \\
\hline & & & $\begin{array}{l}\text { Input } \\
\text { layer }\end{array}$ & $\begin{array}{c}\text { Hidden } \\
\text { layer }\end{array}$ & $\begin{array}{c}\text { Output } \\
\text { layer }\end{array}$ \\
\hline 1 & 1 & 3 & tansig & tansig & tansig \\
\hline 2 & 2 & 9 & logsig & logsig & logsig \\
\hline 3 & 4 & 18 & purelin & purelin & purelin \\
\hline
\end{tabular}
control factors, levels of these factors were determined in Table 3.

The adapted design of Taguchi L27 $\left(3^{5}\right)$ was chosen to determine the optimal control factors of the neural network structure [33]. Table 4 showed the selected mixed orthogonal array of control factors and correlation coefficients of the conducted learning, test and validation of each ANN combination. Mean square error (MSE) and number of iterations are also taken as additional parameters in Table 4. 
Table IV: Taguchi orthogonal array L27 ( $\left.3^{5}\right)$ : Simulation using a neural network with Levenberg-Marquardt training algorithm

\begin{tabular}{|c|c|c|c|c|c|c|c|c|c|c|c|}
\hline $\begin{array}{c}\text { Run } \\
\text { No }\end{array}$ & A & B & C & D & E & R test (RT) & $\begin{array}{c}\text { R validation } \\
(\mathrm{RV})\end{array}$ & R all (Ra) & MSE & $\begin{array}{c}\text { No of iteration } \\
(\text { It })\end{array}$ & SN of R \\
\hline 1 & 1 & 1 & 1 & 1 & 1 & 0,808 & 0,616 & 0,768 & $2,44 \mathrm{E}-01$ & 37 & $-2,908$ \\
2 & 1 & 1 & 1 & 1 & 2 & 0,064 & 0,567 & 0,168 & $1,36 \mathrm{E}+00$ & 15 & $-19,720$ \\
3 & 1 & 1 & 1 & 1 & 3 & 0,944 & 0,789 & 0,913 & $8,12 \mathrm{E}-02$ & 100 & $-1,171$ \\
4 & 1 & 2 & 2 & 2 & 1 & 0,989 & 0,911 & 0,971 & $2,18 \mathrm{E}-06$ & 17 & $-0,399$ \\
5 & 1 & 2 & 2 & 2 & 2 & 0,958 & 0,900 & 0,880 & $9,55 \mathrm{E}-01$ & 9 & $-0,810$ \\
6 & 1 & 2 & 2 & 2 & 3 & 0,999 & 0,998 & 0,999 & $2,66 \mathrm{E}-06$ & 21 & $-0,012$ \\
7 & 1 & 3 & 3 & 3 & 1 & 0,999 & 0,783 & 0,956 & $1,31 \mathrm{E}-08$ & 19 & $-0,942$ \\
8 & 1 & 3 & 3 & 3 & 2 & 0,239 & 0,523 & 0,290 & $9,08 \mathrm{E}-01$ & 8 & $-10,407$ \\
9 & 1 & 3 & 3 & 3 & 3 & 0,690 & 0,384 & 0,638 & $3,03 \mathrm{E}-01$ & 10 & $-5,779$ \\
10 & 2 & 1 & 2 & 3 & 1 & 0,978 & 0,960 & 0,974 & $3,33 \mathrm{E}-02$ & 35 & $-0,261$ \\
11 & 2 & 1 & 2 & 3 & 2 & 0,237 & 0,070 & 0,212 & $9,94 \mathrm{E}-01$ & 19 & $-19,138$ \\
12 & 2 & 1 & 2 & 3 & 3 & 0,920 & 0,560 & 0,856 & $2,16 \mathrm{E}-02$ & 18 & $-2,816$ \\
13 & 2 & 2 & 3 & 1 & 1 & 0,931 & 0,924 & 0,868 & $1,70 \mathrm{E}-04$ & 19 & $-0,854$ \\
14 & 2 & 2 & 3 & 1 & 2 & 0,714 & 0,756 & 0,723 & $9,20 \mathrm{E}-01$ & 100 & $-2,729$ \\
15 & 2 & 2 & 3 & 1 & 3 & 0,958 & 0,719 & 0,906 & $1,30 \mathrm{E}-04$ & 19 & $-1,507$ \\
16 & 2 & 3 & 1 & 2 & 1 & 0,999 & 0,663 & 0,929 & $2,20 \mathrm{E}-07$ & 32 & $-1,693$ \\
17 & 2 & 3 & 1 & 2 & 2 & 0,364 & 0,232 & 0,322 & $9,44 \mathrm{E}-01$ & 14 & $-10,759$ \\
18 & 2 & 3 & 1 & 2 & 3 & 0,701 & 0,453 & 0,653 & $1,34 \mathrm{E}-01$ & 9 & $-4,897$ \\
19 & 3 & 1 & 3 & 2 & 1 & 0,120 & 0,365 & 0,017 & $6,65 \mathrm{E}-01$ & 15 & $-30,970$ \\
20 & 3 & 1 & 3 & 2 & 2 & 0,030 & 0,447 & 0,071 & $1,07 \mathrm{E}+00$ & 8 & $-26,473$ \\
21 & 3 & 1 & 3 & 2 & 3 & 0,437 & 0,596 & 0,474 & $5,42 \mathrm{E}-01$ & 10 & $-6,196$ \\
22 & 3 & 2 & 1 & 3 & 1 & 0,975 & 0,776 & 0,932 & $2,50 \mathrm{E}-02$ & 28 & $-1,099$ \\
23 & 3 & 2 & 1 & 3 & 2 & 0,095 & 0,009 & 0,077 & $1,76 \mathrm{E}+00$ & 11 & $-36,055$ \\
24 & 3 & 2 & 1 & 3 & 3 & 0,833 & 0,426 & 0,755 & $1,70 \mathrm{E}-03$ & 12 & $-4,625$ \\
25 & 3 & 3 & 2 & 1 & 1 & 0,951 & 0,624 & 0,886 & $9,60 \mathrm{E}-04$ & 25 & $-2,172$ \\
26 & 3 & 3 & 2 & 1 & 2 & 0,397 & 0,246 & 0,349 & $9,43 \mathrm{E}-01$ & 14 & $-10,153$ \\
27 & 3 & 3 & 2 & 1 & 3 & 0,964 & 0,583 & 0,886 & $5,06 \mathrm{E}-04$ & & $-2,468$ \\
& & & & & & & & & & 14 \\
\end{tabular}

\subsubsection{Signal to noise and the maintained ANN}

After the creation of Taguchi's design L27 $\left(3^{5}\right)$, the test correlation (RT), validation correlation (RV) and global correlation (Ra) coefficients are used as response data. However, the analysis of Taguchi's orthogonal array by the signal to noise ratio larger is the better is used to maximize the correlation coefficients RT, RV and Ra, according to formula (1).

As shown in Fig. 5, graphs generated of the main effects of correlation coefficients and their interactions in the model for the signal to noise ratio reveal that the structure A1B2C3D1E3 is the best, which means that the architecture of the ANN is as follows: a single hidden layer with nine neurons and the activation functions, logsig at the input layer, tansig at the hidden layer and purelin at the output layer.

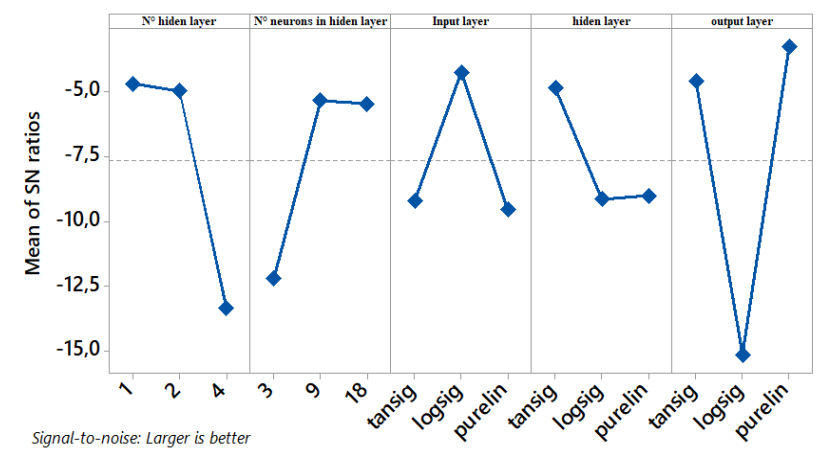

Fig. 5. Main effects plot for signal to noise ratio.
However, according to the combination A1B2C3D1E3 given by signal to noise, The learning results of the ANN with back propagation of the error gradient associated with the Levenberg-Marquardt algorithm are as follows: the correlation between the experimental values and the prediction values of learning is $(\mathrm{RA})=0.9996$, the validation correlation rate is $(\mathrm{RV})=0.9955$ and the overall correlation rate is $(\mathrm{RG})=0.9987$, as illustrated in Fig. 6 .

The optimized ANN performance curve illustrated in Fig. 7, quickly reaches the desired convergence with the Levenberg-Marquardt algorithm. This convergence is reached with only 20 iterations with a very short total learning time.

Based on the correlation coefficients values, it can be seen that the ANN optimized by the Taguchi method is more efficient compared to the ANN optimized by the empirical method. However, at the output layer of the ANN, the results consist of a matrix of detection rates for different types of faults in electric motors, which represent the success rates of the vibration indicators for four rotation speeds. The matrix is composed of 16 lines and 32 columns.

\section{SENSITIVITY TEST}

In this section, to determine the most influential vibration indicators, we have performed a sensitivity analysis for our ANN inputs. Two methods were chosen to determine the most influential parameters on the output of the ANN, the Garson algorithm and the connection weight approach $[34,35]$. Table 5 shows the weights of the input- 
hidden layer of our optimized neural network which were used for the two sensitivity tests.
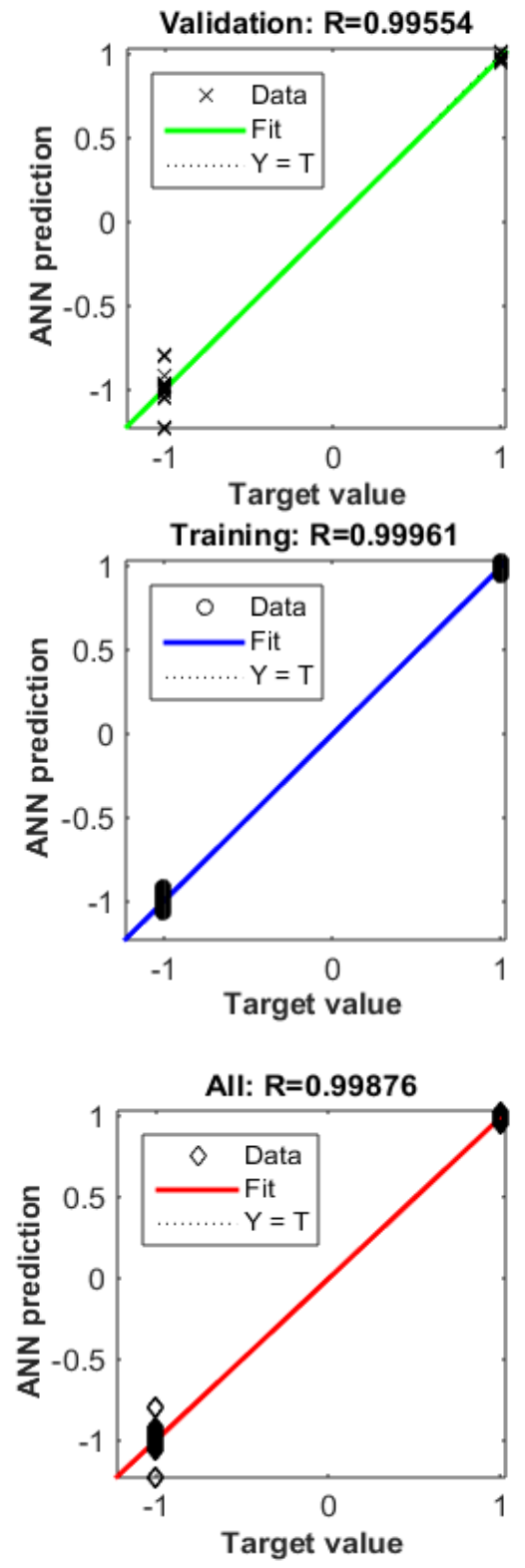

Fig. 6. Correlation coefficients of the optimised ANN with Taguchi method

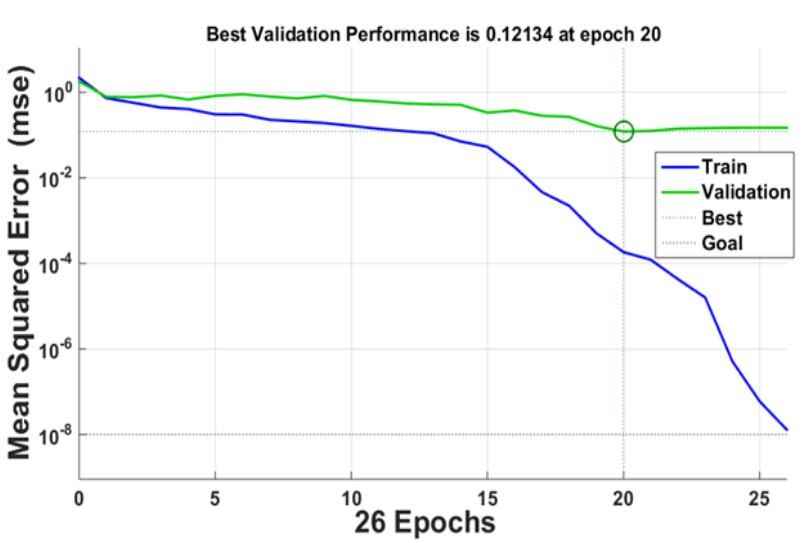

Fig. 7. Best validation performance of the optimised ANN with Taguchi method

Garson's method makes it possible to determine the most sensitive input parameters; the classification of these parameters is carried out by the absolute magnitudes of the weights in the hidden layer. The connection weight method classifies the input parameters of the ANN and determines their influences on its output [36].

Garson's method and the connection weight method are expressed in the Equations (4) and (5) respectively.

$$
\begin{aligned}
& \text { Input }_{x}=\sum_{n=1}^{9} \frac{\mid \text { Hidden }_{x n} \mid}{\sum_{z=1}^{8} \mid \text { Hidden }_{z n} \mid} \\
& \text { Input }_{x}=\sum_{n=1}^{9} \text { Hidden }_{x n}
\end{aligned}
$$

Where, Hidden ${ }_{x n}$ are the absolute magnitudes of the connection weights between the input-hidden and hiddenoutput node, Hidden $_{z n}$ is the absolute magnitudes of the product of the connection weight.

According to the results of Garson method and the connection weight method, the sensitivity of input parameters is established in Table 6 and Table 7 respectively.

Table V: Product of the input-hidden and hidden-output connection weights

\begin{tabular}{|c|c|c|c|c|c|c|c|c|c|}
\hline \multirow{2}{*}{$\mathrm{x}$} & \multicolumn{9}{|c|}{$\mathrm{n}$} \\
\cline { 2 - 11 } & $\begin{array}{c}\text { Hidden } \\
\mathrm{x} 1\end{array}$ & $\begin{array}{c}\text { Hidden } \\
\mathrm{x} 2\end{array}$ & $\begin{array}{c}\text { Hidden } \\
\mathrm{x} 3\end{array}$ & $\begin{array}{c}\text { Hidden } \\
\mathrm{x} 4\end{array}$ & $\begin{array}{c}\text { Hidden } \\
\mathrm{x} 5\end{array}$ & $\begin{array}{c}\text { Hidden } \\
\mathrm{x} 6\end{array}$ & $\begin{array}{c}\text { Hidden } \\
\mathrm{x} 7\end{array}$ & $\begin{array}{c}\text { Hidden } \\
\mathrm{x} 8\end{array}$ & $\begin{array}{c}\text { Hidden } \\
\mathrm{x} 9\end{array}$ \\
\hline maximum value & 2,437 & 1,170 & 1,632 & 0,338 & 0,667 & $-1,433$ & 0,252 & $-0,452$ & $-0,027$ \\
\hline RMS value & $-0,268$ & 1,015 & 2,049 & 1,655 & $-3,047$ & 0,245 & 3,796 & $-3,512$ & $-0,752$ \\
\hline $\begin{array}{c}\text { Mean square } \\
\text { value }\end{array}$ & $-3,067$ & $-1,274$ & $-1,827$ & 1,826 & $-5,054$ & 6,029 & $-0,388$ & 1,657 & $-0,245$ \\
\hline Variance & $-3,159$ & $-0,811$ & $-1,305$ & $-1,364$ & $-5,345$ & 5,743 & 0,106 & 2,839 & $-3,521$ \\
\hline Kurtosis factor & 1,048 & $-2,628$ & 0,916 & 2,557 & $-3,176$ & 7,501 & 2,606 & 1,218 & $-2,268$ \\
\hline Crest factor & 1,384 & 2,372 & 5,239 & 4,788 & 8,787 & 0,941 & $-4,750$ & $-4,981$ & 2,878 \\
\hline Clearance factor & $-3,274$ & $-5,856$ & $-4,248$ & $-3,989$ & $-0,179$ & $-5,370$ & 4,051 & 14,346 & 1,078 \\
\hline Peak to peak & 4,257 & 0,763 & $-0,818$ & $-1,236$ & 0,663 & $-2,605$ & $-2,125$ & $-6,006$ & 1,553 \\
\hline
\end{tabular}


Table VI: Relative importance with Garson's algorithm

\begin{tabular}{|l|c|c|c|}
\hline \multicolumn{1}{|c|}{ Input } & $\begin{array}{c}\text { Relative } \\
\text { importance }\end{array}$ & $\begin{array}{c}\text { Relative } \\
\text { importance(\%) }\end{array}$ & Rank \\
\hline $\begin{array}{l}\text { maximum } \\
\text { value }\end{array}$ & 0,414 & 4,60 & 8 \\
\hline RMS value & 0,778 & 8,64 & 7 \\
\hline $\begin{array}{l}\text { Mean square } \\
\text { value }\end{array}$ & 0,925 & 10,28 & 5 \\
\hline Variance & 1,131 & 12,57 & 4 \\
\hline Kurtosis factor & 1,148 & 12,75 & 3 \\
\hline Crest factor & 1,779 & 19,77 & 2 \\
\hline $\begin{array}{l}\text { Clearance } \\
\text { factor }\end{array}$ & 1,910 & 21,22 & 1 \\
\hline Peak to peak & 0,915 & 10,17 & 6 \\
\hline
\end{tabular}

Table VII: Relative importance with connection weights

\begin{tabular}{|l|c|c|c|}
\hline \multicolumn{1}{|c|}{ Input } & $\begin{array}{c}\text { Relative } \\
\text { importance }\end{array}$ & $\begin{array}{c}\text { Relative } \\
\text { importance (\%) }\end{array}$ & Rank \\
\hline $\begin{array}{l}\text { maximum } \\
\text { value }\end{array}$ & 4,585 & 9,48 & 5 \\
\hline RMS value & 1,182 & 2,44 & 8 \\
\hline $\begin{array}{l}\text { Mean square } \\
\text { value }\end{array}$ & $-2,342$ & 4,84 & 7 \\
\hline Variance & $-6,816$ & 14,10 & 3 \\
\hline Kurtosis factor & 7,774 & 16,08 & 2 \\
\hline Crest factor & 16,658 & 34,45 & 1 \\
\hline $\begin{array}{l}\text { Clearance } \\
\text { factor }\end{array}$ & $-3,441$ & 7,12 & 6 \\
\hline Peak to peak & $-5,553$ & 11,49 & 4 \\
\hline
\end{tabular}

As represented in Fig. 8, Clearance factor and crest factor are the most important input parameters according to the Garson's method; they represent $21 \%$ and $20 \%$, respectively. The connection weight method classifies crest factor, Kurtosis and Variance as the most input parameter, they represent $34 \%, 16 \%$ and $14 \%$, respectively. Hence, according to the two methods crest factor is the most sensitive parameter.

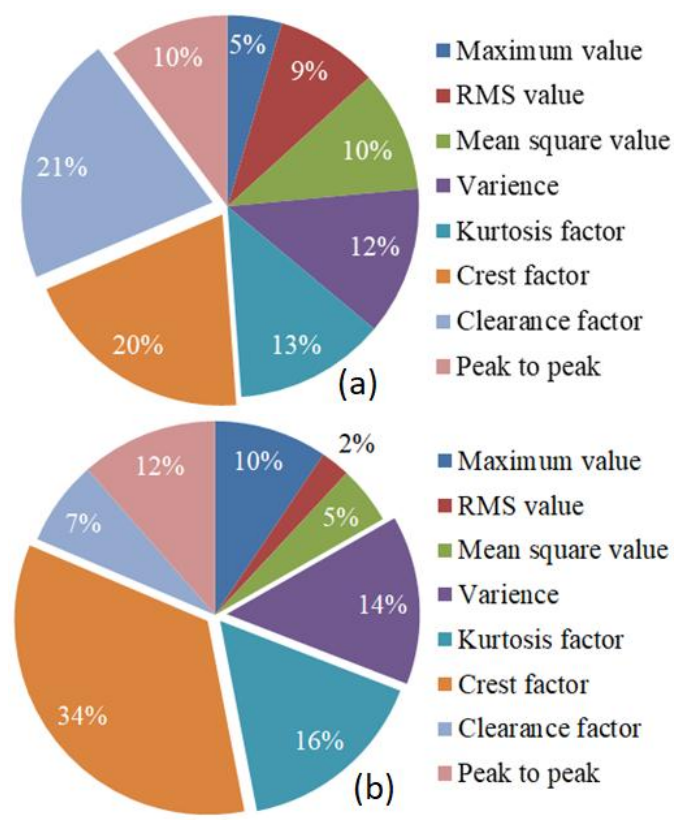

Fig.8. Relative importance of the parameters, (a) Garson's algorithm and (b) connection weights algorithm

\section{CONCLUSIONS}

In this work, a monitoring and diagnostic approach was developed. The method is based on an artificial intelligence system optimized with Taguchi's design. The signals collected from the different measurement conditions were used to calculate eight time descriptors, which are then used for the input layer of our neuron network. However, the optimization of the architecture of the ANN was carried out using the Taguchi experimental design method. In our case, five factors and three levels, the L27 orthogonal array was the most suitable.

In order to calculate the difference between the experimental values and the desired values, the loss function converted into an $\mathrm{S} / \mathrm{N}$ ratio was used to determine A1B2C3D1E3 as the optimal structure of the ANN. The learning of ANN with A1B2C3D1E3 structure and learning algorithm LevenbergMarquardt, gave correlation coefficients values that approximates one hundred percent, the correlation rate of learning is $(\mathrm{RA})=0.9996$, the validation correlation rate is $(\mathrm{RV})=0.9955$ and the overall correlation rate is $(\mathrm{RG})=0.9987$. The optimized ANN converges quickly to the desired output, with an MSE close to zero and only 20 iterations.

Garson's method and the connection weight method used to determine the most sensitive indicators at the input layer of the ANN revealed that crest factor has been found to be the most important input parameter followed by kurtosis, Clearance factor and Variance. The results obtained with this proposed system are efficient and accurate to detect different induction motor faults.

\section{ACKNOWLEDGEMENTS}

The authors would like to thank the Directorate General for Scientific Research and Technological Development (DGRSDT) for financial support (PRFU code: A01L09UN410120190002). Also, they would like to express their appreciation for the valuable time that anonymous reviewers have dedicated to the review process.

\section{REFERENCES}

1. Choudhary A, Goyal D, Shimi SL, Akula A. Condition Monitoring and Fault Diagnosis of Induction Motors: A Review. Arch Computat Methods Eng 2019; 26: 1221-1238. https://doi.org/10.1007/s11831-018-9286-z.

2. Chen Z, Deng S, Chen X, Li C, Sanchez RV, Qin H. Deep neural networks-based rolling bearing fault diagnosis, Microelectronics Reliability 2017; 75: 327-333 https://doi.org/10.1016/j.microrel.2017.03.006. 
3. Da Silva AM, Povinelli RJ, Demerdash NA, Induction machine broken bar and stator shortcircuit fault diagnostics based on three-phase stator current envelopes. IEEE Trans. Ind. Electron. 2008; 55: $1310-1318$ https://doi.org/10.1109/TIE.2007.909060

4. Verucchi C, Bossio J, Bossio G, Acosta G. Misalignment detection in induction motors with flexible coupling by means of estimated torque analysis and MCSA. Mechanical Systems and Signal Processing 2016; 80: 570-581. https://doi.org/10.1016/j.ymssp.2016.04.035.

5. Glowacz A, Glowacz W, Glowacz Z, Kozik J. Early fault diagnosis of bearing and stator faults of the single-phase induction motor using acoustic signals. Measurement 2018; 113: 1-9.

https://doi.org/10.1016/j.measurement.2017.08.036.

6. Tsypkin M.Induction motor condition monitoring: Vibration analysis technique - diagnosis of electromagnetic anomalies. IEEE AUTOTESTCON, Schaumburg, IL 2017: 1-7. https://doi.org/10.1109/AUTEST.2017.8080483.

7. Culbert I, Letal J. Signature Analysis for Online Motor Diagnostics: Early Detection of Rotating Machine Problems Prior to Failure. IEEE Industry Applications Magazine 2017; 23: 76-81. https://doi.org/10.1109/MIAS.2016.2600684.

8. Filippetti F, Franceschini G, Tassoni C, Vas P. Recent developments of induction motor drives fault diagnosis using AI techniques. IEEE Transactions on Industrial Electronics 2000; 47: 994-1004. https://doi.org/10.1109/41.873207.

9. Burriel-ValenciaJ, Puche-Panadero R, MartinezRoman J, Sapena-Bano A, Pineda-Sanchez M, Perez-Cruz J, Riera-Guasp M. Automatic Fault diagnostic system for induction motors under transient regime optimized with expert systems. Electronics 2019; 8. https://doi.org/10.3390/electronics8010006

10. Guerra de Araujo CruzA. Delgado Gomes R, Antonio Belo F, Cavalcante Lima Filho A. A hybrid system based on fuzzy logic to failure diagnosis in induction motors. IEEE Latin America Transactions 2017; 15 : 1480-1489.

https://doi.org/10.1109/TLA.2017.7994796.

11. Ali MZ, Shabbir MNSK, Liang X, Zhang Y, Hu T. Machine learning-based fault diagnosis for singleand multi-faults in induction motors using measured stator currents and vibration signals. IEEE Transactions on Industry Applications 2019; 55: 2378-2391.

https://doi.org/10.1109/TIA.2019.2895797

12. Lakehal A. Bayesian graphical model based optimal decision-making for fault diagnosis of critical induction motors in industrial applications. Bulletin of the Polish Academy of Sciences: Technical Sciences 2020; 68: 467-476. https://doi.org/10.24425/bpasts.2020.133374

13. Zhang $\mathrm{Y}, \mathrm{Hu} \mathrm{T}$, Liang $\mathrm{X}$, Ali MZ, Shabbir MNSK. Fault detection and classification for induction motors using genetic programming. In: Sekanina L, Hu T, Lourenço N, Richter H, García-Sánchez P. (eds) Genetic Programming. EuroGP 2019. Lecture Notes in Computer Science, Vol 11451. Springer, Cham

https://doi.org/10.1007/978-3-030-16670-0_12

14. Pezzani CM, Fontana JM, Donolo PD, De Angelo $\mathrm{CH}$, Bossio GR, Silva LI. SVM-based system for broken rotor bar detection in induction motors. IEEE ANDESCON, Santiago de Cali 2018: 1-6.

https://doi.org/10.1109/ANDESCON.2018.8564627

15. Lashkari N, Azgomi HF, Poshtan J, Poshtan M. Asynchronous motors fault detection using ANN and fuzzy logic methods. IEEE Energy Conversion Congress and Exposition (ECCE), Milwaukee, WI, 2016: 1-5. https://doi.org/10.1109/ECCE.2016.7854890.

16. Cho HC, Knowles J, Fadali MS, Lee KS. Fault detection and isolation of induction motors using recurrent neural networks and dynamic bayesian modeling. IEEE Transactions on Control Systems Technology 2010; 18: 430-437.

https://doi.org/10.1109/TCST.2009.2020863.

17. Rajeswaran N, Lakshmi Swarupa M, Sanjeeva Rao $\mathrm{T}$, Chetaswi K. Hybrid artificial intelligence based fault diagnosis of SVPWM voltage source inverters for induction motor. Materials Today: Proceedings 2018; 5: 565-571. https://doi.org/10.1016/j.matpr.2017.11.119.

18. Unal M, Onat M, Demetgul M, Kucuk H. Fault diagnosis of rolling bearings using a genetic algorithm optimized neural network. Measurement 2014; 58: 187-196.

https://doi.org/10.1016/j.measurement.2014.08.041.

19. Ghate VN, Dudul SV. Optimal MLP neural network classifier for fault detection of three phase induction motor. Expert Systems with Applications 2010; 37: 3468-3481.

https://doi.org/10.1016/j.eswa.2009.10.041.

20. Gui-li Y, Shi-wei Q, Mi G. Motor fault diagnosis of RBF neural network based on immune genetic algorithm. 25th Chinese Control and Decision Conference (CCDC), Guiyang 2013: 1060-1065. https://doi.org/10.1109/CCDC.2013.6561081.

21. Gangsar P, Tiwari R. Signal based condition monitoring techniques for fault detection and diagnosis of induction motors: A state-of-the-art review. Mechanical Systems and Signal Processing 2020; 144: 106908 . https://doi.org/10.1016/j.ymssp.2020.106908.

22. Kumar Verma A, Sarangi S, H. Kolekar M. Misalignment fault detection in induction motor using rotor shaft vibration and stator current signature analysis. International Journal of Mechatronics and Manufacturing Systems 2013; 6: 422-436.

https://doi.org/10.1504/IJMMS.2013.058519

23. Abd-el-Malek MK. Abdelsalam A, E. Hassan O. Induction motor broken rotor bar fault location detection through envelope analysis of start-up current using Hilbert transform. Mechanical Systems and Signal Processing 2017; 93: 332-350. https://doi.org/10.1016/j.ymssp.2017.02.014.

24. Khoualdia T, Lakehal A, Chelli Z. Practical investigation on bearing fault diagnosis using massive vibration data and artificial neural network". In: Farhaoui Y. (eds) Big Data and Networks Technologies. BDNT 2019. Lecture Notes in Networks and Systems, Vol 81. Springer, Cham. https://doi.org/10.1007/978-3-030-23672-4 9

25. Dhamande LB. Chaudhari M. Compound gearbearing fault feature extraction using statistical features based on time-frequency method. Measurement 2018; 125: 63-77. https://doi.org/10.1016/j.measurement.2018.04.059. 
26. Laissaoui A, Bouzouane B, Miloudi A, Hamzaoui N. Perceptive analysis of bearing defects (Contribution to vibration monitoring). Applied Acoustics 2018; 140: 248-255.

https://doi.org/10.1016/j.apacoust.2018.06.004.

27. WangZH, Gong DY, Li X, Li GT, Zhang DH. Prediction of bending force in the hot strip rolling process using artificial neural network and genetic algorithm (ANN-GA). International Journal of Advanced Manufacturing Technology 2017; 93: 3325-3338.

https://doi.org/10.1007/s00170-017-0711-5

28. Khoualdia K, Hadjadj Aoul E, Khoualdia T. (in press). Application of optimised neural networks models in gears and bearings faults diagnosis. International Journal of Vehicle Noise and Vibration.

Chen PC, Yang MW, Wei CH, Lin SZ. Selection of blended amine for $\mathrm{CO} 2$ capture in a packed bed scrubber using the Taguchi method. International Journal of Greenhouse Gas Control 2016; 45: 245252. https://doi.org/10.1016/j.ijggc. 2015.11.017.

29. Huang CN, Yu CC. Integration of Taguchi's method and multiple-input, multiple-output ANFIS inverse model for the optimal design of a water-cooled condenser. Applied Thermal Engineering 2016; 98: 605-609.

https://doi.org/10.1016/j.applthermaleng.2015.11.11 2

30. Xie J, Yuan C. Parametric study of ice thermal storage system with thin layer ring by Taguchi method. Applied Thermal Engineering 2016; 98: 246-255.

https://doi.org/10.1016/j.applthermaleng.2015.12.03 $\underline{8}$.

31. Nor NHM, Muhamad N, Ibrahim MHI, Ruzi M, Jamaludin KR. Optimization of injection molding parameter of Ti-6Al-4 $\mathrm{V}$ powder mix with palm stearin and polyehylene for the highest green strength by using Taguchi method. International Journal of Mechanical and Materials Engineering (IJMME) 2011; 6(1): 126-132.

32. Khoualdia T, Hadjadj Aoul E, Bouacha K, Ould Abdeslam D. Multi-objective optimization of ANN fault diagnosis model for rotating machinery using grey rational analysis in Taguchi method. Int $\mathrm{J}$ Adv Manuf Technol 2017; 89: 3009-3020. https://doi.org/10.1007/s00170-016-9278-9

33. Garson DG. Interpreting neural network connection weights. Arti. Intell. Expert 1991; 6: 46-51.

34. Acharyya R, Dey A. Assessment of bearing capacity for strip footing located near sloping surface considering ANN model. Neural Comput \& Applic 2019; 31: 8087-8100. https://doi.org/10.1007/s00521-018-3661-4

35. Acharyya R, Dey A, Kumar B. Finite element and ANN-based prediction of bearing capacity of square footing resting on the crest of $c-\varphi$ soil slope. International Journal of Geotechnical Engineering 2020; 14(2): 176-187.

https://doi.org/10.1080/19386362.2018.1435022

Received 2020-07-30

Accepted 2021-02-05

Available online 2021-02-09

Tarek KHOUALDIA received his Magister from the University of Skikda, in 2007. He obtained his Doctor's degree in Electromechanical from the University of Badji Mokhtar, Annaba, Algeria in 2016. His research interests include dynamic monitoring and vibration analysis

to diagnose mechanical systems.

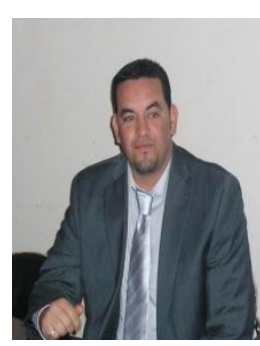

Abdelaziz LAKEHAL received the Engineer degree in Industrial Maintenance, the Magister degree in Mechanical Engineering, the $\mathrm{PhD}$ degree, and the HDR (Habilitation to supervise research activities in Electromechanical Engineering), in 2004, 2007, 2013, and 2016 respectively. From $04 / 2012$ to $10 / 2014$, he was appointed as Lecturer in the National Higher School of Technology, Algiers. In 2014, he moved to MohamedChérif Messaadia University, Souk-Ahras, Algeria, where he is currently Full Professor. His research interests include maintenance, quality reliability and safety, fault diagnosis and prediction, sensors.

Pr Abdelaziz LAKEHAL is the author and co-author of many journal and conference papers. He has served on the technical program committees of numerous conferences, and is an editorial board member and reviewer of some journals.

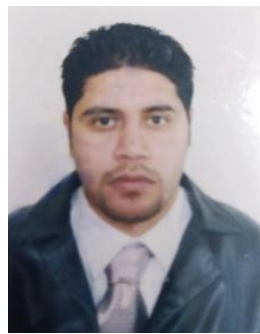

Zoubir CHELLI He has studied at university of Guelma, Algeria, and received the Engineer degree in electrical engineering (2002). In 2015 he obtained his PHD degree in electrical engineering at the University of Annaba and the "HDR" (Habilitation à diriger des recherches) in 2019. Dr Chelli is Associate Professor of the Department of electrical engineering, Mohammed Chérif Messaadia University, Algeria.

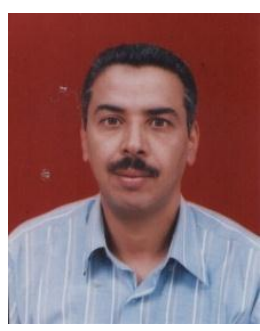

mechanical systems.

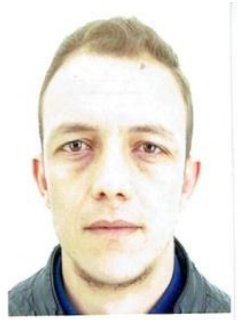

Kais KHOUALDIA is an Engineer in Electromechanical from the University of Badji Mokhtar, Annaba, Algeria in 1991. He obtained his Magister in Electromechanical from same University in 1996. His research interests in condition based maintenance and diagnosis of

Nessaib KARIM was born on 24 august 1991; he got a master's degree in 2017 , currently working toward a Ph.D degree in electromechanical engineer at Mohammed Chérif Messaadia University, Algeria. His research interests include fault diagnosis and prediction, AI methods. 